\title{
Establishment of alternative social order to the hospital in the setting of COVID-19
}

\section{Establecimiento de un orden social alternativo al hospital en el contexto de COVID-19}

\author{
José L. García-Vigil1* and José L. García-Álvarez²
}

${ }^{1}$ Faculty of Medicine, Universidad Nacional Autónoma de México; ${ }^{2}$ Continuous Admission Service, Specialty Hospital, Centro Médico Nacional Siglo XXI, Instituto Mexicano del Seguro Social. Ciudad de México, México

We share our reflections picking up on the final part of the editorial article by Liz Hamui Sutton entitled "Hospital symbolic boundaries during the COVID-19 pandemic", where she delves into the semantics and semiotics of hospital symbolic boundaries in the context of the COVID-19 pandemic, which are more visible when the patient develops severe disease and experiences multiple organ failure, especially due to extensive severe lung injury. The author brings up relevant definitions of medical care, curative rather than preventive medicine within hospital spaces, the quality of the sick person who becomes a patient within its facilities and the personal and familiar conflict this entails, both due to the distancing and social isolation hospitalization implies, and to the physical and emotional vulnerability associated with the loss of health status, which can culminate in death and definitively seeing the family off.

Our answer in an affirmative sense is that there is a viable alternative that is tacitly accepted by Mexican families who have suffered the loss of a loved one due to the COVID-19 pandemic. We start from the arguments put forward in the manuscript.

Following the criterion of hospitalizing critically ill patients with oxygen saturation below $80 \%$ on home treatment with $3-5 \mathrm{~L} / \mathrm{min}$ of oxygen, if there is space in hospitals during the new outbreak phase, these patients will most likely require intubation and mechanical ventilation in the intensive care unit, where only $30 \%$ survive; furthermore, at hospital discharge, they leave with sequelae and $50 \%$ risk of death in the course of the following year.

These patients may choose to continue treatment at home, aware that death is likely, but at home and with the family, with the support of medical personnel and equipment, medications, instruments and other materials provided by the health-care institution.

Benefits include a compassionate death at home, with quality and warmth in the last days or hours of life, which, needless to say, is more cost-effective than in the hospital.

\section{Conflict of interests}

The authors declare that they have no conflicts of interest relevant to the performance of this work.

\section{Funding}

The authors declare that they have not received any funding or support for carrying out this work.

\section{References}

1. Hamui-Sutton L. Las fronteras simbólicas del hospital durante la pandemia de COVID-19. Gac Med Mex. 2021;157:225-7. 